Rubrikherausgeber:

Tom Schaberg, Rotenburg (Koordination)

Roland Buhl, Mainz

Adrian Gillissen, Leipzig
Karl Häußinger, Gauting

Rolf Merget, Bochum

Claus Vogelmeier, Marburg

T. O. F. Wagner, Frankfurt
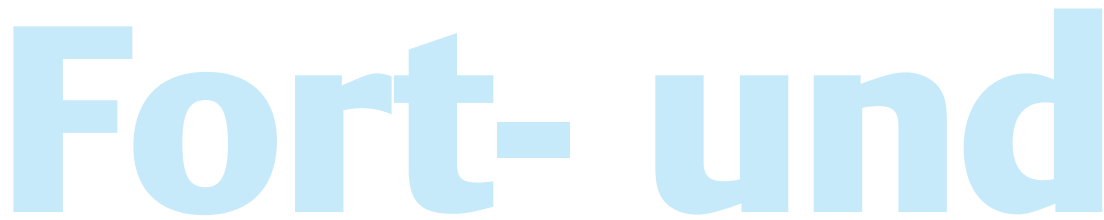

.
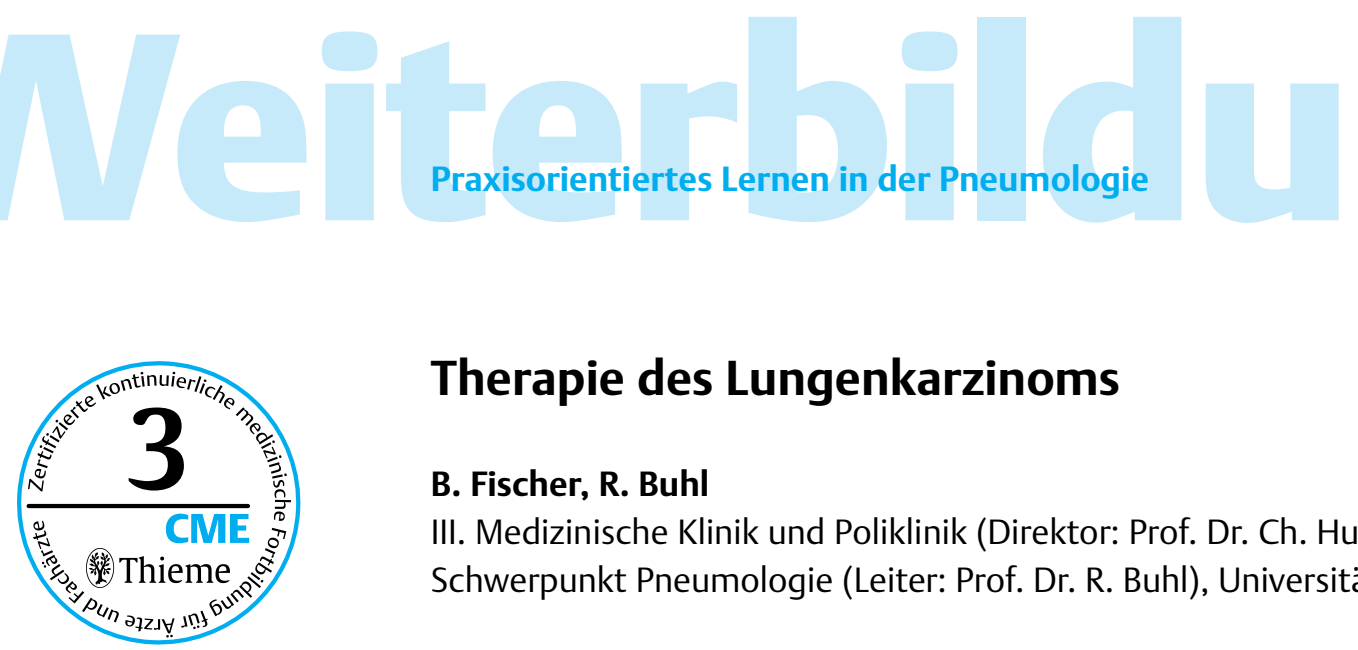

\title{
Therapie des Lungenkarzinoms
}

\section{B. Fischer, R. Buhl}

III. Medizinische Klinik und Poliklinik (Direktor: Prof. Dr. Ch. Huber), Schwerpunkt Pneumologie (Leiter: Prof. Dr. R. Buhl), Universitätskliniken Mainz

\section{Weiterbildungsziele}

In diesem Beitrag sollen folgende Weiterbildungsziele vermittelt werden:

1. Therapie des nicht-kleinzelligen Lungenkarzinoms (NSCLC)

1.1 Stadium I und II

1.2 Stadium III

1.3 Stadium IIIA

1.4 Adjuvante Chemotherapie nach vollständig reseziertem NSCLC

1.5 Stadium IIIB

1.6 Pancoast-Tumoren

1.7 Stadium IV

1.8 Molekular zielgerichtete Therapie
2. Therapie des kleinzelligen Lungenkarzinoms

2.1 Therapieentscheidungen nach Tumorstadien

2.2 Stadium I und II

2.3 Stadium III

2.4 Stadium IV

2.5 Prophylaktische Schädelbestrahlung

2.6 Erhaltungstherapie

2.7 Rezidiv

2.8 Dosisdichte

3. Schlussbemerkung 
In der Europäischen Union liegt die Inzidenz des Lungenkarzinoms bei 52,5/100000 pro Jahr, die Mortalität bei 48,7/100000 pro Jahr. Zigarettenrauchen ist bei Männern für $90 \%$, bei den Frauen für $80 \%$ der Erkrankungen verantwortlich.

In den Stadien I und II dominiert die chirurgische Therapie.
Das Lungenkarzinom ist eine weltweit führende Krebstodesursache. In der Europäischen Union liegt die Inzidenz bei 52,5/100000 pro Jahr, die Mortalität bei $48,7 / 100000$ pro Jahr [1,2]. Für Deutschland wird pro Jahr mit etwa 40000 Neuerkrankungen gerechnet. Das 5-Jahres-Überleben ist in den vergangenen Jahrzehnten nur gering gestiegen und beträgt etwa 13-15\% [3]. Trotz dieser ernüchternden Feststellung konnten Fortschritte in der Behandlung erreicht werden. So ist das mediane Überleben der Patienten mit nicht-kleinzelligem Lungenkarzinom in lokal fortgeschrittenen Stadien durch verbesserte Kombination der einzelnen Behandlungsprinzipien (multimodale Ansätze) und im metastasierten Stadium durch Einführung neuer Medikamente (Zytostatika der 3. Generation und molekular zielgerichtete Substanzen) angestiegen. Der mit Abstand wichtigste Risikofaktor für die Entwicklung eines Lungenkarzinoms ist Zigarettenrauchen, etwa 90\% aller Fälle bei Männern und 80\% der Erkrankungen bei Frauen werden durch Rauchen verursacht. Unabhängig von allen Überlegungen zur Therapie ist die primäre Prävention durch Unterlassen des inhalativen Zigarettenrauchens daher die wichtigste Maßnahme zur Bekämpfung des Lungenkarzinoms.

Die Lungenkarzinome werden aus tumorbiologischen, prognostischen und therapeutischen Gründen in kleinzellige (SCLC) und nicht-kleinzellige Karzinome (NSCLC) unterschieden. Im Wesentlichen wird das nicht-kleinzellige Lungenkarzinom in die drei histologischen Subtypen Adenokarzinom, Plattenepithelkarzinom und großzelliges Karzinom unterteilt, deren Therapie aber bisher weitgehend gleichartig ist.

\section{Therapie des nicht-kleinzelligen Lungenkarzinoms (NSCLC)}

$\mathrm{Zu}$ Beginn der therapeutischen Überlegungen ist die möglichst genaue Diagnostik des Tumorstadiums nach dem TNM-System durchzuführen (siehe CME-Artikel zur Diagnostik). Die Therapieentscheidung setzt die möglichst exakte Festlegung des Tumorstadiums voraus.

\subsection{Stadium I und II}

In den Stadien I und II $\left(\mathrm{T}_{1} \mathrm{~N}_{0} ; \mathrm{T}_{2} \mathrm{~N}_{0} ; \mathrm{T}_{1} \mathrm{~N}_{1} ; \mathrm{T}_{2} \mathrm{~N}_{1} ; \mathrm{T}_{3} \mathrm{~N}_{0}\right)$ dominiert die chirurgische Therapie. Wann immer von Seiten der Lungenfunktion sowie der Begleiterkrankungen des Patienten möglich, ist eine kurative Resektion in Form einer Lobektomie oder Pneumonektomie mit systematischer Lymphknotendissektion anzustreben. Das Langzeitüberleben ( 5 Jahre) beträgt nach Angaben in großen Studien im Stadium IA $\left(\mathrm{T}_{1} \mathrm{~N}_{0}\right)$ zwischen $67 \%$ und $75 \%$ und im Stadium IB $\left(\mathrm{T}_{2} \mathrm{~N}_{0}\right) 57 \%$. Im Stadium II sind nach kurativer Resektion 5-Jahres-Überlebensraten von 52 - 55\% im Stadium IIA und 33 - 38 \% im Stadium IIB zu erwarten.

Es ist von großem Vorteil für die postoperative Lungenfunktion und damit die Lebensqualität des Patienten, wenn in geeigneten Fällen von den Möglichkeiten einer Manschettenresektion Gebrauch gemacht wird (z.B. Ostiumtumoren des rechten Oberlappens). Auf diese Weise ergibt sich auch eine günstigere Ausgangslage für eine adjuvante Chemotherapie (siehe unten). Nach Möglichkeit sollte also zur Resektion eine Vorstellung in einer thoraxchirurgisch ausgerichteten Abteilung mit entsprechender Erfahrung erfolgen.

Eine postoperative Strahlentherapie ist im Stadium I und II nicht angezeigt, es sei denn die Schnittränder sind nicht tumorfrei und eine Nachresektion kann nicht durchgeführt werden. Dagegen ist bei funktioneller Inoperabilität oder wenn die/der Erkrankte eine Operation ablehnt eine primäre, kurativ intendierte Radiatio mit 60-70 Gy mit einer Einzeldosis von nicht mehr als $2 \mathrm{~Gy}$ angezeigt. Ist die Lungenfunktion stark eingeschränkt, muss auch für eine Strahlentherapie das individuelle Risiko sehr sorgsam überdacht und bei der Definition des Zielvolumens berücksichtigt werden. Das Media- 
Primäre Operation bei geringgradigem $\mathrm{N}_{2}$-Befall anstreben.

Im Stadium IIIA N $\mathrm{N}_{2}$ multipel oder IIIA bulky $\mathrm{N}_{2}$ gibt es zur Zeit keine allgemein akzeptierte Standardtherapie. Patienten in diesem Stadium im guten Allgemeinzustand und mit geringer Komorbidität sollten daher innerhalb kontrollierter klinischer Studien behandelt werden. stinum wird mit 50 Gy bestrahlt. Bei kleinem Primärtumor und schlechter Lungenfunktion ist es gerechtfertigt, das Mediastinum nicht zu bestrahlen [4].

\subsection{Stadium III}

Das Stadium III ist ausgesprochen heterogen, wenn man bedenkt, welche unterschiedlichen Tumorausdehnungen innerhalb dieses Stadiums subsumiert werden. Gleichzeitig werden in diesem Stadium Therapieempfehlungen kontrovers diskutiert, so dass geeignete Patienten möglichst innerhalb klinischer Studien behandelt werden sollten!

\subsection{Stadium IIIA}

Das Stadium IIIA umfasst nach der TNM-Formel die Tumorausdehnung $\mathrm{T}_{3} \mathrm{~N}_{1}$ und $\mathrm{T}_{1-3} \mathrm{~N}_{2}$. Die Behandlungsempfehlungen innerhalb dieser Tumorausdehnung unterscheiden sich deutlich je nach $\mathrm{N}$-Status.

Ein $\mathrm{N}_{1}$-Befall und/oder lediglich der Befall einer (einzelnen!) Lymphknotenstation in $\mathrm{N}_{2}$-Position ohne Kapseldurchbruch bzw. ein lediglich postoperativ entdeckter, mikroskopisch positiver $\mathrm{N}_{2}$-Befund (minimal $\mathrm{N}_{2}$-disease) wird grundsätzlich einem anderen Behandlungsalgorithmus unterzogen als der häufig bereits radiologisch verdächtige IIIA $\left(\mathrm{N}_{2}\right)$-Befund mehrerer mediastinaler Lymphknoten in $\mathrm{N}_{2}$-Position oder $\mathrm{N}_{2}$-Lymphknoten mit Kapseldurchbruch („bulky disease“).

Der möglichst exakten prätherapeutischen Evaluation des mediastinalen Lymphknotenbefalls durch Biopsie (Mediastinoskopie, transbronchiale Nadelaspiration [TBNA]) kommt hohe Bedeutung zu. Bei entsprechender Erfahrung und Verfügbarkeit stellt die PET-Untersuchung eine viel versprechende Methode zur prätherapeutischen Evaluation dar. So ermöglicht ein negatives PET ein primär operatives Vorgehen, da ein mediastinaler Lymphknotenbefall mit hoher Sensitivität und Spezifität unwahrscheinlich ist. Dagegen empfiehlt sich bei positivem PET die mediastinale Lymphknotenbiopsie zur histologischen Verifizierung des Befundes, da falsch positive Befunde durch granulomatöse entzündliche Veränderungen hervorgerufen werden können. Wenn nach entsprechender Evaluation ein Stadium IIIA mit lediglich $\mathrm{N}_{1}$-Befall oder mit geringgradigem $\mathrm{N}_{2}$-Befall (nur eine Lymphknotenstation befallen) vorliegt, ist bei ausreichender funktioneller Reserve die Operation (Lobektomie oder Manschettenresektion oder Pneumektomie jeweils mit systematischer Lymphknotendissektion) der primäre therapeutische Schritt.

Bei postoperativ pathologisch bestätigtem $\mathrm{N}_{2}$ oder bei $\mathrm{R}_{1,2}$-Resektion ist eine postoperative Radiatio indiziert [5].

Der bereits klinisch-radiologisch evidente $\mathrm{N}_{2}$-Befall (IIIA $\mathrm{N}_{2}$ multipel oder IIIA bulky $\mathrm{N}_{2}$ ) ist mit einer schlechten Prognose assoziiert mit Fünfjahres-Überlebensraten von ca. $18 \%$ [4]. In dieser Situation ist eine allgemein akzeptierte Standardtherapie derzeit nicht etabliert. Nach Möglichkeit sollten diese Patienten in einem Zentrum (interdisziplinäre Lungenkarzinomkonferenz) vorgestellt werden. Besonders empfehlenswert wäre die Aufnahme des Patienten in ein multimodales Therapiekonzept, das die Synergien von Chemotherapie, Strahlentherapie und Operation ausnutzt, z.B.: induktive Chemotherapie gefolgt von Operation oder induktive Chemoradiotherapie gefolgt von Operation (Abb.1 -6) oder definitive Chemoradiotherapie. So stellte die EORTC (European Organisation for Research and Treatment of Cancer) Lung Cancer Group auf dem diesjährigen amerikanischen Krebskongress ihre randomisierte Phase-III-Studie zur thorakalen Strahlentherapie (60 Gray) versus Operation bei histologisch/zytologisch verifiziertem $\mathrm{N}_{2}$-Stadium vor [6]. 572 Patienten starteten in das Protokoll, das mit 3 Zyklen platinbasierter Chemotherapie begann. Von den auf die Chemotherapie ansprechenden Patienten wurden 333 für die beiden Therapiearme (definitive Radiotherapie versus Operation) randomisiert. Das 2-Jahres-Überleben betrug im Operationsarm 

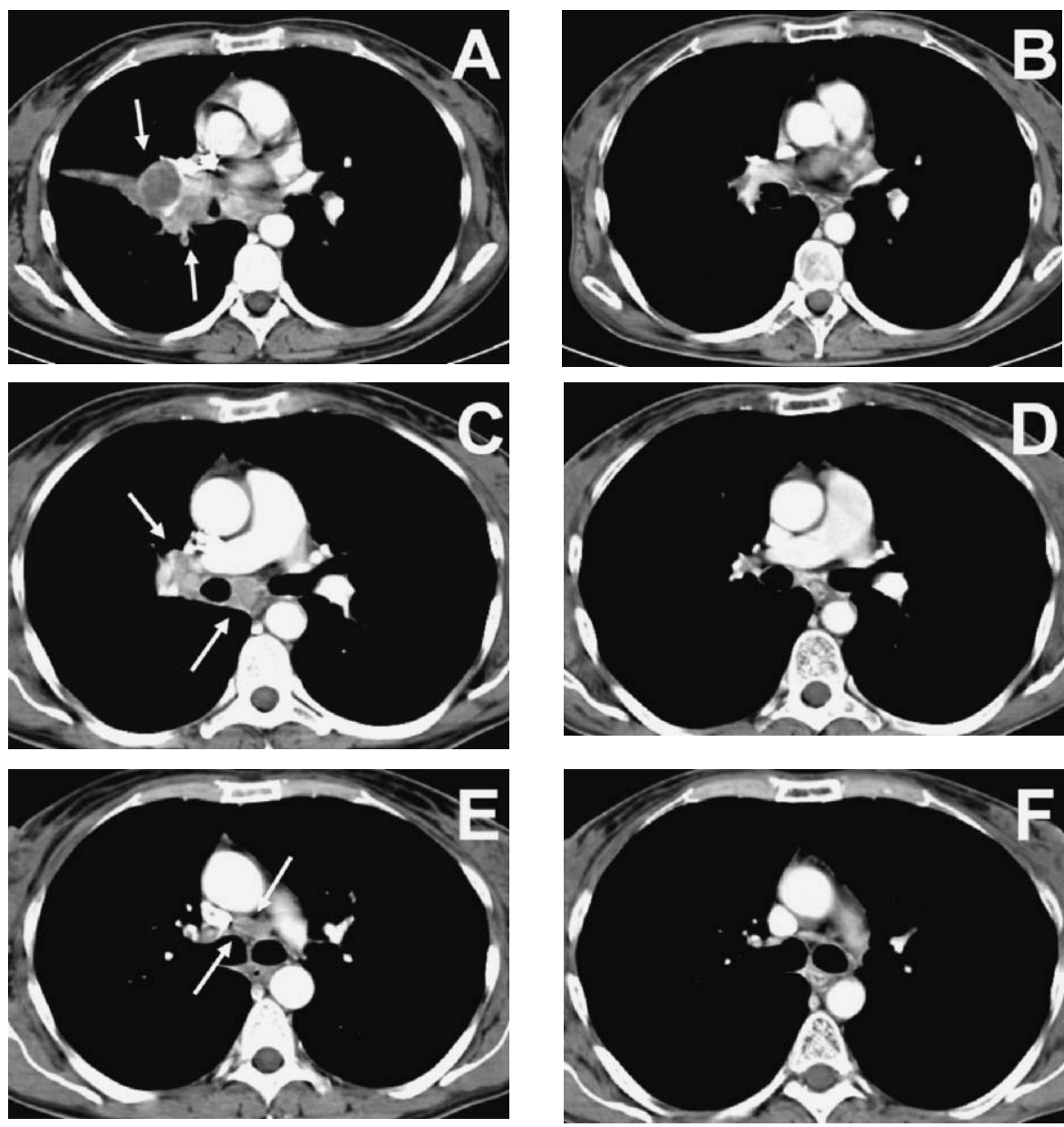

Abb. 1-6 Radiomorphologischer Verlauf im Computertomogramm bei einer 40-jährigen Patientin im guten Allgemeinzustand (ECOG: 1) mit lokal fortgeschrittenem Plattenepithelkarzinom (NSCLC IIIA, $N_{2}$ ) jeweils vor (A, C, E) und nach (B, D, F) neoadjuvanter Chemoradiotherapie. Die Pfeile zeigen die tumorösen Veränderungen zu Therapiebeginn. Die anschließende Resektion konnte kein vitales Tumorgewebe mehr nachweisen $\left(\mathrm{pT}_{0}, \mathrm{pN}_{0(0 / 9)}, \mathrm{pM}_{\mathrm{x}}, \mathrm{pR}_{0}\right)$. Die Autoren danken Prof. Dr. M. Thelen, Mainz, für die Überlassung der Computertomogramme.

35\%, im Bestrahlungsarm 41\%; das 5-Jahres-Überleben betrug im Operationsarm 15,7\%, im Bestrahlungsarm 14\%. In dieser Studie zeigte also die Operation gegenüber der Strahlentherapie, jeweils nach induktiver Chemotherapie, keinen Vorteil bezüglich Überleben oder progressionsfreiem Überleben.

Außerhalb klinischer Studienprotokolle empfiehlt die ESMO (European Society for Medical Oncology) eine präoperative Chemotherapie (Induktionschemotherapie) für resektable IIIA( $\left(\mathrm{N}_{2}\right)$-Stadien. Im Lichte der neuen positiven Daten für die adjuvante Chemotherapie (siehe unten) werden kommende klinische Studien auch der Frage nachgehen müssen, ob die Chemotherapie in diesen Fällen besser präoperativ oder postoperativ gegeben werden sollte.

\subsection{Adjuvante Chemotherapie nach vollständig reseziertem NSCLC}

1995 belegte eine Metaanalyse für die adjuvante Chemotherapie in den Stadien I- IIIA eine $13 \%$-ige Reduktion des Sterberisikos gleichbedeutend mit einem absoluten Überlebensvorteil von $5 \%$ nach 5 Jahren [7]. Seither zeigten mehrere multizentrische, prospektive, randomisierte Studien mit ganz überwiegend modernen Kombinationschemotherapien der dritten Generation an über 3500 Patienten den lebensverlängernden Effekt einer adjuvanten, nach erfolgreicher Resektion des Tumors gegebenen Chemotherapie [8-11] (Tab.1). Somit kann die adjuvante Chemotherapie als evidenz-basier- 
Das Stadium IIIB stellt eine Indikation für eine kombinierte Chemoradiotherapie dar. In besonders günstigen Situationen kann sekundär eine kurativ intendierte Operation erfolgen.

Derzeit entspricht die prophylaktische Schädelbestrahlung beim NSCLC nicht einem evidenz-basierten medizinischen Standard.
Tab. 1 Überblick über die aktuellen adjuvanten Chemotherapiestudien beim NSCLC (adjuvante Therapie versus Beobachtung)

\begin{tabular}{lllll}
\hline & IALT-Studie [8] & JBR.10-Studie [9] & CALGB 9633-Studie [10] & ANITA-Studie [11] \\
\hline Patienten (n) & 1867 & 482 & 344 & 840 \\
\hline Stadium & I, II, III & IB, II & IB & IB, II, IIIA \\
adjuvante & Cisplatin-haltig; & Cisplatin plus Vino- & Carboplatin plus & Cisplatin plus Vino- \\
Therapie & bei einigen & relbin; keine & Paclitaxel; keine & relbin; bei einigen \\
& Radiatio & Radiatio & Radiatio & Radiatio \\
\hline $\begin{array}{l}\text { 5-Jahres- } \\
\text { Überleben }\end{array}$ & $\begin{array}{l}\text { 44,5\% versus 40,4\% } \\
\text { P }\end{array}$ & $69 \%$ versus 54\% & $71 \% *$ versus 59\%* & $51,2 \%$ versus $42,6 \%$ \\
\hline
\end{tabular}

*4-Jahres-Überleben

tes Therapieregime für das Stadium II und IIIA gelten und wird voraussichtlich in den kommenden Leitlinien der Fachgesellschaften empfohlen werden. Die adjuvante Chemotherapie setzt allerdings voraus, dass sich die Patienten in gutem Allgemeinzustand befinden, eine zügige Erholung von der Operation eingetreten ist und keine signifikanten Komorbiditäten, die üblicherweise dem Einsatz einer Chemotherapie entgegenstehen könnten, vorliegen. Speziell zu Patienten im Alter über 75 Jahren und zum Therapiestart nach mehr als 2 Monaten postoperativ liegen bisher keine Daten vor. Üblicherweise wurde innerhalb der erwähnten Studien 4-6 Wochen postoperativ mit der adjuvanten Chemotherapie begonnen. Allerdings war in der JBR.10-Studie als auch in der ANITA-Studie der positive Effekt der adjuvanten Chemotherapie nicht im Stadium IB nachweisbar (Abb.7-10). Dagegen prüfte die CALGB-Studie nur das Stadium IB und war deutlich positiv. Eine klare Empfehlung zum Stadium IB ist daher aktuell nicht möglich.

\subsection{Stadium IIIB}

In diesem Stadium werden $\mathrm{T}_{4}$-Tumoren (z. B. direkte Invasion des Mediastinums, Infiltration großer Gefäße, Hauptcarinabefall) und/oder Tumoren mit Beteiligung von Lymphknoten in $\mathrm{N}_{3}$-Position (z.B. kontralateral mediastinal, kontralateral hilär, supraklavikulär) zusammengefasst. Unter Würdigung des Allgemeinzustandes (ECOG 0 und 1, in Einzelfällen auch 2) gilt heute das Stadium IIIB als Indikation für eine kombinierte Chemoradiotherapie [12]. Die Charakterisierung des Allgemeinzustandes nach der Eastern Cooperative Oncology Group (ECOG) ist Tab. 2 zu entnehmen. Die simultane Therapie ist der sequenziellen Gabe überlegen und sollte soweit organisatorisch möglich bei Patienten in gutem Allgemeinzustand vorgesehen werden [3,13]. Weitere Verbesserungsmöglichkeiten ergeben sich durch den Einsatz einer hyperfraktionierten, akzelerierten Strahlentherapie (1,5 Gray jeweils zweimal täglich über 2 - 3 Wochen) [14]. In besonders günstigen Situationen, bei jüngeren Patienten, gutem Ansprechen auf die Chemo- oder Chemoradiotherapie kann in Einzelfällen auch ein Stadium IIIB sekundär einer kurativ intendierten Operation zugeführt werden. So wurde von der Essener Gruppe bei 174 Patienten im Stadium IIIB ein 5-Jahres-Überleben von 26\% beschrieben [15]. Ein $\mathrm{N}_{3}$-Befall von supraklavikulären Lymphknoten allerdings gilt weiterhin als klares Indiz für prognostische Inoperabilität.

Aus den Therapiestudien zur multimodalen Behandlung des Stadiums IIIA/IIIB ist bekannt, dass etwa $20 \%$ der Rezidive in dieser Situation ausschließlich das Zerebrum betreffen [16]. Derzeit rekrutiert eine multizentrische, nordamerikanische, randomisierte Phase-III-Studie (RTOG L-0214), die Patienten innerhalb eines multimodalen, kurativ intendierten Therapiealgorithmus entweder einer prophylaktischen Schädelbestrahlung oder einem Beobachtungsarm zuordnet. Derzeit entspricht die prophylaktische Schädelbestrahlung beim nicht-kleinzelligen Lungenkarzinom außerhalb klinischer Studien nicht einem evidenz-basierten medizinischen Standard. 

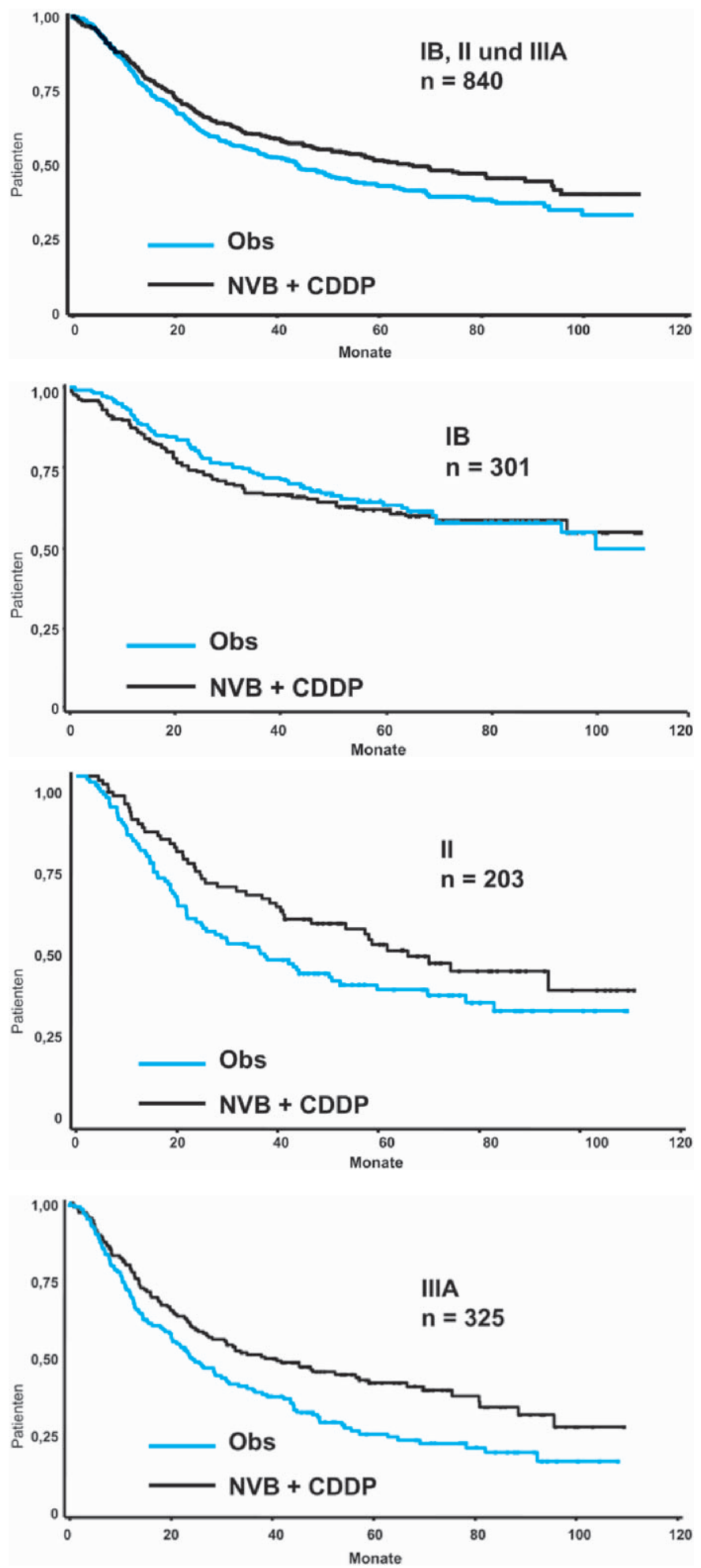

Abb. 7-10 Überleben in der ANITA-Studie [modifiziert nach [11] ]. Adjuvante Chemotherapie in den Stadien IB, II und IIIA des NSCLC. Obs. = Beobachtungsarm; NVB + CDDP = postoperative adjuvante Chemotherapie mit Vinorelbin/Cisplatin. Signifikanter Vorteil für den Therapiearm im Gesamtkollektiv ( $p=0,013)$. Das Stadium IB scheint in dieser Studie nicht zu profitieren. Die Stadien II und IIIA profitieren deutlich.

Ein maligner Pleuraerguss bzw. Perikarderguss als $\mathrm{T}_{4}$-Kriterium führt zu einer Einteilung in das Stadium IIIB („IIIB/Pleuraerguss“ bzw. „IIIB wet“). Der Nachweis von IIIB wet qualifiziert nicht mehr für eine kurativ intendierte lokale Radiatio. Diese Patienten werden daher wie ein Stadium IV einer palliativen systemischen Therapie zugeführt. Ggf. profitiert der Patient von einer Talkumpleurodese bzw. Bleomycinperikardese. 
Die Chemotherapie ist akzeptierter Standard für Patienten im Stadium IV des NSCLC in gutem Allgemeinzustand. Die Verfügbarkeit der neuen Zytostatika der dritten Generation (Docetaxel, Gemcitabin, Paclitaxel, Vinorelbin) hat die Optionen spürbar erweitert und verbessert.
Tab. 2 Performance-Status, Einteilung nach ECOG (eastern cooperative oncology group)

0 normale, uneingeschränkte Aktivität, wie vor der Erkrankung

1 Einschränkung bei körperlicher Anstrengung, gehfähig, leichte körperliche Arbeit möglich (im Sitzen)

2 gehfähig, Selbstversorgung möglich, nicht arbeitsfähig, kann 50\% der Wachzeit aufstehen

3 nur begrenzte Selbstversorgung möglich, 50\% und mehr der Wachzeit an Bett und Stuhl gebunden

4 völlig pflegebedürftig, keinerlei Selbstversorgung möglich, völlig an Bett oder Stuhl gebunden

\subsection{Pancoast-Tumoren}

Es handelt sich um Tumoren der Lungenspitze (Sulcus-superior-Tumore), die meist dem Stadium $T_{3}$, bei z. B. der Infiltration eines Wirbelkörpers auch dem Stadium $\mathrm{T}_{4}$ angehören. Aufgrund der besonderen Lagebeziehung zu benachbarten Strukturen mit der Problematik des Erreichens tumorfreier operativer Absetzungsränder besteht eine hohe lokale Rezidivneigung. Bisheriger Standard in dieser Situation ist die präoperative Bestrahlung mit 40-50 Gy mit 2-3 Wochen nach der Bestrahlung anschließender Resektion in Form einer Lobektomie mit ggf. Resektion von A. und V. subclavia, unterem Plexusfaszikel und Querfortsätzen gefolgt von einer komplementären Bestrahlung des ehemaligen Tumorgebietes bis $60 \mathrm{~Gy}$ („Sandwichverfahren“) und ggf. mediastinaler Nachbestrahlung. Zunehmend wird in den letzten Jahren in Analogie zu den im Stadium IIIA/B üblichen Behandlungsprotokollen eine präoperative Chemoradiotherapie durchgeführt.

\subsection{Stadium IV}

In den vergangenen 10 Jahren hat sich die Chemotherapie als Standardbehandlung im metastasierten Stadium des nicht-kleinzelligen Lungenkarzinoms etabliert. Im Vergleich zu best supportive care (BSC) werden sowohl Überlebenszeiten als auch Symptomkontrolle und Lebensqualität positiv beeinflusst. Die Verfügbarkeit der neuen Zytostatika der dritten Generation (Docetaxel, Gemcitabin, Paclitaxel, Vinorelbin) hat die Optionen spürbar erweitert. Entsprechend den Empfehlungen mehrerer Fachgesellschaften ist eine Kombination eine dieser neuen Substanzen mit Cisplatin oder Carboplatin (Tab. 3) evidenzbasierte Therapieempfehlung bei Patienten in gutem Allgemeinzustand. Mit diesen Therapieregimen wird ein medianes Überleben von 7-10 Monaten und ein 1-Jahres-Überleben von etwa 40\% im Stadium IIIB/IV erreicht [24], während unter BSC 4-5 Monate bzw. 10-15\% beobachtet wurden [7]. Obwohl Carboplatin international eine akzeptierte Substanz in der Therapie des NSCLC ist, besteht in Deutschland derzeit nur eine Zulassung für das kleinzellige Lungenkarzinom. Die Kombinationen aus jeweils zwei der neuen Zytostatika ohne platinhaltigen Kombinationspartner erzielen hinsichtlich des Überlebens vergleichbare Resultate und wurden daher in den aktuellen Empfehlungen der American Society of Clinical Oncology aus dem Jahre 2003 gleichwertig empfohlen [12]. Die Wahl im Einzelfall sollte sich vor allem an dem potenziellen Toxizitätsspektrum der Therapie ausrichten. Die First-lineBehandlung sollte bei Ansprechen 3 bis 4 Zyklen umfassen [24]. Es muss besonders betont werden, dass diese Empfehlungen für Patienten in gutem Allgemeinzustand (ECOG 0 und 1 [Tab. 2]) gelten. In nahezu allen Studien wurden Patienten mit schlechterem Allgemeinzustand von Anfang an nicht eingeschlossen oder im Verlauf der Studie wegen hoher Toxizitätsraten und Komplikationen ausgeschlossen. Daher sollten Patienten in schlechterem Allgemeinzustand (ECOG 2) individuell therapiert werden.

Prinzipiell gelten die Empfehlungen auch für ältere Patienten [25]. Im Allgemeinen wird bei älteren Patienten (70 Jahre und älter) eine Monotherapie mit einem Drittgenerations-Chemotherapeutikum empfohlen, bei geringer Komorbidität und guter sonstiger Organfunktion sind auch platinhaltige Kombinationen möglich. Für Patienten im 
Tab. 3 Chemotherapieprotokolle für das nicht-kleinzellige Lungenkarzinom

\begin{tabular}{|c|c|c|}
\hline \multicolumn{3}{|c|}{ Cisplatin/Gemcitabin [17] } \\
\hline Gemcitabin & $1000 \mathrm{mg} / \mathrm{m}^{2}$ & 30 Minuten Infusion Tag 1, 8, 15 \\
\hline Cisplatin ${ }^{\mathrm{a}}$ & $100 \mathrm{mg} / \mathrm{m}^{2}$ & 60 - 120 Minuten Infusion Tag 1 \\
\hline \multicolumn{3}{|c|}{ Wiederholung alle 4 Wochen } \\
\hline \multicolumn{3}{|c|}{ Cisplatin/Docetaxel $[17,18]$} \\
\hline Docetaxel $^{b}$ & $75 \mathrm{mg} / \mathrm{m}^{2}$ & 60 Minuten Infusion Tag 1 \\
\hline Cisplatin & $75 \mathrm{mg} / \mathrm{m}^{2}$ & $60-120$ Minuten Infusion Tag 1 \\
\hline \multicolumn{3}{|c|}{ Docetaxelgabe vor Cisplatin, Wiederholung alle 3 Wochen } \\
\hline \multicolumn{3}{|c|}{ Carboplatin/Paclitaxel [17] } \\
\hline Paclitaxel $^{c}$ & $225 \mathrm{mg} / \mathrm{m}^{2}$ & 3 Stunden Infusion Tag 1 \\
\hline Carboplatin & AUC 6 & Kurzinfusion Tag 1 \\
\hline \multicolumn{3}{|c|}{ Paclitaxelgabe vor Carboplatin, Wiederholung alle 3 Wochen } \\
\hline \multicolumn{3}{|c|}{ Cisplatin/Vinorelbin $[18,19]$} \\
\hline Vinorelbin ${ }^{d}$ & $25 \mathrm{mg} / \mathrm{m}^{2}$ & 6-10 Minuten Infusion wöchentlich \\
\hline Cisplatin $^{\mathrm{a}}$ & $100 \mathrm{mg} / \mathrm{m}^{2}$ & $60-120$ Minuten Infusion Tag 1 \\
\hline \multicolumn{3}{|c|}{ Wiederholung alle 4 Wochen } \\
\hline \multicolumn{3}{|c|}{ Paclitaxel/Cisplatin [20] } \\
\hline Paclitaxel $^{c}$ & $200 \mathrm{mg} / \mathrm{m}^{2}$ & 3 Stunden Infusion Tag 1 \\
\hline Cisplatin $^{\mathrm{a}}$ & $80 \mathrm{mg} / \mathrm{m}^{2}$ & 30 Minuten Infusion nach Paclitaxel Tag 1 \\
\hline \multicolumn{3}{|c|}{ Wiederholung alle 3 Wochen } \\
\hline \multicolumn{3}{|c|}{ Gemcitabin/Docetaxel [21] } \\
\hline Gemcitabin & $1000 \mathrm{mg} / \mathrm{m}^{2}$ & 30 Minuten Infusion Tag 1 und Tag 8 \\
\hline Docetaxel $^{b}$ & $85 \mathrm{mg} / \mathrm{m}^{2}$ & 60 Minuten Infusion vor Gemcitabin Tag 8 \\
\hline \multicolumn{3}{|c|}{ Wiederholung alle 3 Wochen } \\
\hline \multicolumn{3}{|c|}{ Gemcitabin/Vinorelbin [22] } \\
\hline Gemcitabin & $1000 \mathrm{mg} / \mathrm{m}^{2}$ & 30 Minuten Infusion Tag 1 und Tag 8 \\
\hline Vinorelbin ${ }^{d}$ & $25 \mathrm{mg} / \mathrm{m}^{2}$ & 15 Minuten Infusion Tag 1 und Tag 8 \\
\hline \multicolumn{3}{|c|}{ Wiederholung alle 3 Wochen } \\
\hline \multicolumn{3}{|c|}{ Paclitaxel/Gemcitabin [23] } \\
\hline Paclitaxel $^{c}$ & $200 \mathrm{mg} / \mathrm{m}^{2}$ & 3 Stunden Infusion Tag 1 vor Gemcitabin \\
\hline Gemcitabin & $1000 \mathrm{mg} / \mathrm{m}^{2}$ & 30 Minuten Infusion Tag 1 und Tag 8 \\
\hline
\end{tabular}

${ }^{a}$ Cisplatingabe erfordert entsprechende Hydrierung und Antiemese!

${ }^{\mathrm{b}}$ Die Gabe von Docetaxel erfordert Prämedikation mit Dexamethason.

' Die Gabe von Paclitaxel erfordert eine entsprechende Prämedikation zur Vermeidung von Hypersensitivitätsreaktionen (Dexamethason plus Diphenhydramin oder Dimetinden plus Ranitidin oder Cimetidin).

${ }^{d}$ Nachspülen mit $250 \mathrm{ml}$ physiologischer Kochsalzlösung zur Vermeidung einer Phlebitis empfohlen.

Im Rezidiv ist bei gutem Allgemeinzustand eine Zweitlinientherapie empfohlen.
ECOG-Performancestatus 3 oder 4 ist der Stellenwert einer Chemotherapie beim NSCLC nicht gesichert.

Eine Besonderheit innerhalb der Patienten im Stadium IV sind jene Fälle, die lediglich eine einzelne Hirnmetastase oder Nebennierenmetastase aufweisen. In dieser Situation kann der Betroffene von einer Resektion (Primärtumor und singuläre Metastase) profitieren, 5-Jahres-Überlebensraten von 10-20\% sind möglich. Eine adjuvante Chemotherapie in diesem Setting wurde zwar nicht geprüft, sollte aber erwogen werden.

Im Rezidiv ist bei gutem Allgemeinzustand eine Zweitlinientherapie empfohlen. Durch die Studien von Shepherd [26] und Fossella [27] entwickelte sich die second line Gabe von Docetaxel zu einem etablierten Vorgehen. Durch die Entwicklung des Antifolats Pemetrexed hat eine weitere Substanz in dieser Indikation an Bedeutung gewonnen. In der Phase-III-Studie von Hanna und Mitarbeitern [28] konnte gezeigt werden, dass Pemetrexed bei vergleichbarer Effektivität in der Zweitlinientherapie mit einem mittleren Überleben von 8 Monaten und einem 1-Jahres-Überleben von 29\% ein günstigeres Toxizitätsprofil aufweist. 
Die Fortschritte auf dem Gebiet der molekular zielgerichteten Therapie zeigen sich in der Zulassung von Erlotinib in den USA und in der Schweiz für die Zweit- und Drittlinientherapie beim inkurablen NSCLC. Die Zulassung in Deutschland steht unmittelbar bevor.

\subsection{Molekular zielgerichtete Therapie}

In den letzten Jahren ist die molekular zielgerichtete Therapie auch des Lungenkarzinoms zu einem der wichtigsten aktuellen Themen geworden [29]. Die Fortschritte auf diesem Gebiet zeigen sich in der Zulassung von Erlotinib in den USA und in der Schweiz für die Zweit- und Drittlinientherapie beim inkurablen NSCLC. Erlotinib ist ein oral verfügbarer, kleinmolekularer Inhibitor der Tyrosinkinase des epidermalen Wachstumsfaktorrezeptors (epidermal growth factor receptor=EGFR). EGFR ist auf Tumorzellen des NSCLC überexprimiert. Vermehrte Aktivität von EGFR verstärkt die Tumorangiogenese, stimuliert die Zellproliferation, fördert die Metastasierung und hemmt den programmierten Zelltod (Apoptose). Erlotinib besetzt hochselektiv die ATP-Bindungsstelle der intrazellulären Domäne des EGF-Rezeptors und antagonisiert so den Signaltransduktionsweg des EGF-Rezeptors. In einer plazebokontrollierten Phase-III-Studie an 731 Patienten mit NSCLC nach first line oder second line Chemotherapie erhielten die Patienten $150 \mathrm{mg}$ Erlotinib per os pro Tag $(n=488)$ oder Plazebo $(n=243)$ [30]. Unter Erlotinib betrug die mediane Überlebenszeit 6,7 Monate im Vergleich zu 4,7 Monaten mit Plazebo ( $p=0,001$ ). Nach einem Jahr lebten in der Erlotinib-Gruppe noch $31 \%$ und in der Plazebo-Gruppe 21 \% der Patienten. Häufigste unerwünschte Wirkung war ein Hautausschlag (Rash), der sich meist spontan oder in ausgeprägten Fällen (Abb.11) nach einer Therapiepause zurückbildete. Aus klinischen Beobachtungen ließen sich Kriterien erarbeiten, die mit erhöhter Ansprechwahrscheinlichkeit einhergingen: Nichtraucher, Frauen, Adenokarzinom, japanischer Patient. Aus frühen klinischen Studien ergibt sich der Eindruck, dass bronchiolo-alveoläre Karzinome als Untergruppe der Adenokarzinome häufiger als andere histologische Typen des NSCLC auf EGFR-Inhibitoren ansprechen. Mutationen, die im EGFR-Gen für die intrazelluläre ATP-Bindungsstelle kodieren, sagen ein Ansprechen auf die Therapie vorher. Zur Zeit ist eine Steuerung der Therapie über Erfassung des Mutationsstatus in der klinischen Praxis noch nicht möglich. Außerdem hat sich gezeigt, dass auch Patienten ohne Mutation von einer Erlotinib-Therapie profitieren [30].

Ein weiterer Fortschritt konnte im Frühjahr diesen Jahres mit der erfolgreichen Testung des gegen VEGF (vascular endothelial growth factor) gerichteten, monoklonalen Antikörpers Bevacizumab durch die ECOG-Studiengruppierung in den USA verzeichnet werden. Bevacizumab ist bereits in der First-line-Therapie des metastasierten kolorektalen Karzinoms zugelassen. In einer prospektiven, randomisierten Studie an $842 \mathrm{~Pa}-$

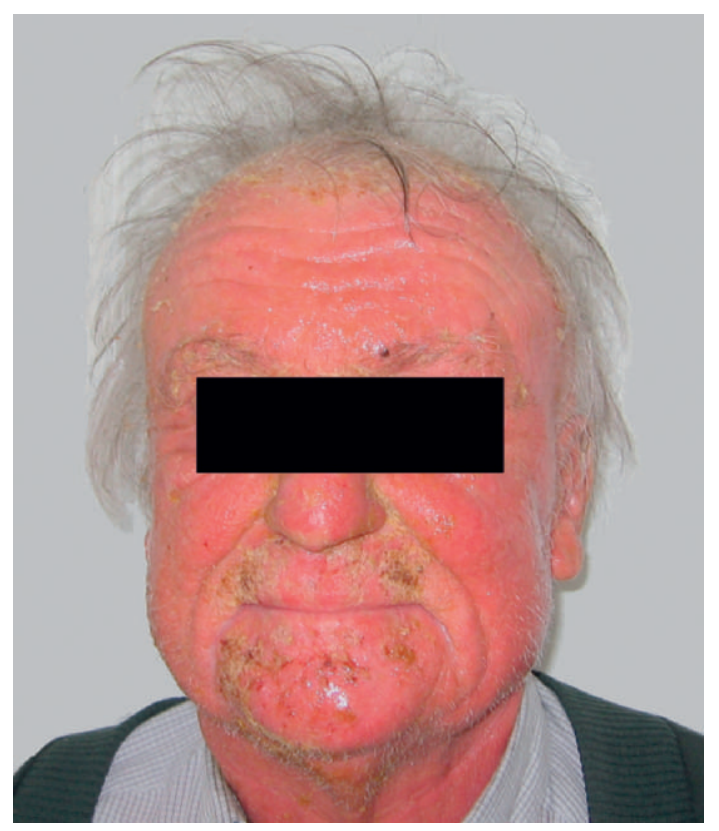

Abb. 11 Ausgeprägtes Exanthem unter Therapie mit einem oralen EGFR-Tyrosinkinaseinhibitor. 
tienten zeigte Bevacizumab zusätzlich zu einer Chemotherapie mit Paclitaxel plus Carboplatin eine signifikante Verbesserung der Ansprechrate (10\% vs. $27 \%$ ), des progressionsfreien Überlebens (4,5 vs. 6,4 Monate) und des medianen Überlebens (10,2 vs. 12,5 Monate) [31]. Wegen des in Phase-II-Studien gesehenen Nebenwirkungspotenzials (Hämoptysen) wurden Plattenepithelkarzinome nicht in die Studie aufgenommen. An Nebenwirkungen sind im Wesentlichen pulmonale Blutungen mit einem Anteil von 1,3\% Grad III/IV und die Entwicklung einer Hypertonie mit einem Anteil von 6\% Grad III/IV zu erwähnen. Diese Studie wird zur Zeit in Europa reproduziert.

\section{Therapie des kleinzelligen Lungenkarzinoms}

Bei etwa 15-20\% der Patienten liegt ein kleinzelliges Lungenkarzinom vor. Der Anteil des kleinzelligen Lungenkarzinoms an allen thorakalen Neoplasien ist rückläufig und hat beispielsweise in den USA von 17,4\% im Jahr 1986 auf 13,8\% in 1998 abgenommen [32].

Aufgrund des differierenden klinischen Managements ist das kleinzellige gesondert von den nicht-kleinzelligen Lungenkarzinomen zu besprechen. Die hohe Proliferationsrate und die frühzeitige Metastasierung führen zu einer sehr ungünstigen Prognose mit einem mittleren Überleben ohne Therapie von 3 Monaten bei lokal begrenzter Erkrankung und von 6 Wochen bei metastasierter Erkrankung. Daher ist nach Diagnosestellung eine möglichst umgehende Therapieeinleitung erforderlich.

Wegen der schnellen Zellproliferation und der Neigung zur frühzeitigen lymphogenen und hämatogenen Metastasierung sowie dem guten Ansprechen auf eine Chemotherapie stellt diese die führende Behandlungsmodalität dar. Bei noch lokal begrenzter Tumorausdehnung werden ergänzend lokale Therapiemaßnahmen in kurativer Intention eingesetzt. Dennoch erliegt die große Mehrzahl der Patienten dieser aggressiven Erkrankung.

\subsection{Therapieentscheidungen nach Tumorstadien}

Die klassische Stadieneinteilung des kleinzelligen Lungenkarzinoms erfolgt nach der Veterans Administration Lung Cancer Study Group in „limited-stage disease“ und „extensive-stage disease“. Die Stadieneinteilung der Lungenkarzinome nach der aktuellen Fassung der TNM-Klassifikation der UICC (1997) wurde auch in Hinblick auf eine Anwendbarkeit beim kleinzelligen Lungenkarzinom entwickelt und findet aufgrund der detaillierteren Beschreibung prognostischer Untergruppen zunehmend beim kleinzelligen Lungenkarzinom Anwendung.

\subsection{Stadium I und II}

In den seltenen Stadien I und II besteht ein kurativ intendierter Therapieansatz.

In den seltenen Stadien I $\left(\mathrm{T}_{1-2} \mathrm{~N}_{0} \mathrm{M}_{0}\right)$ und II $\left(\mathrm{T}_{1-2} \mathrm{~N}_{1} \mathrm{M}_{0}\right)$, die nur etwa bei $10 \%$ aller Erkrankten vorliegen, besteht ein kurativ intendierter Therapieansatz. Häufig ergibt sich die Diagnose dieses Stadiums und der Histologie erst aus dem pathologischen Befund einer Resektion eines ätiologisch ungeklärten Rundherdes mit anschließender Lobektomie und mediastinaler Lymphknotenresektion. In diesem Fall schließen sich adjuvant nach Wundheilung 4 Zyklen einer Chemotherapie an. Liegt die histologische Sicherung bereits zu Therapiebeginn vor, wird die Chemotherapie vor der Resektion durchgeführt. Der Stellenwert der konsolidierenden mediastinalen Bestrahlung in den Stadien I und II ist derzeit offen. Bis zum Vorliegen valider Daten wird außerhalb von Studien die konsolidierende Radiotherapie als dritte Behandlungsmodalität in dieser Situation unabhängig vom Lymphknotenstatus empfohlen. Ein 5-Jahres-Überleben von $50 \%$ ist erreichbar. 
Im Stadium III des SCLC wird die simultane Applikation der Chemo- und Strahlentherapie bevorzugt.

Im Stadium IV des SCLC kann durch Auswahl aus der Fülle möglicher Kombinationstherapien nahezu auf alle Komorbiditäten Rücksicht genommen werden.

\subsection{Stadium III}

Es handelt sich um Patienten im Stadium „limited disease“ $>T_{2}$ und/oder $>N_{1}$. Typischerweise können alle Tumorformationen innerhalb eines Strahlenfeldes erfasst werden. Es werden 4 Zyklen einer Chemotherapie appliziert, anschließend wird konsolidierend oder additiv bestrahlt. Naturgemäß besteht keine Bestrahlungsindikation bei malignem Pleuraerguss, obwohl formal noch ein Stadium limited disease bzw. nach der UICC-Stadiengruppierung ein Stadium IIIB „wet“ $\left(\mathrm{T}_{4}\right)$ besteht. Unter Berücksichtigung der Möglichkeit, die Bestrahlung bereits nach dem ersten Chemotherapiezyklus oder ab Therapiebeginn simultan durchführen zu können, gilt die Kombination aus Cisplatin und Etoposid in dieser Situation als Standardchemotherapie. Bei gleichzeitiger Thoraxbestrahlung ist unter dieser Kombination mit einer geringeren Lungen-, Hautund Ösophagustoxizität zu rechnen als unter Verwendung anderer zytostatischer Kombinationen. Details der Sequenz und des Zeitpunktes der Bestrahlung im Rahmen der Chemoradiotherapie des kleinzelligen Lungenkarzinoms im Stadium limited disease sind weiterhin Gegenstand klinischer Studienprotokolle. Der simultanen Applikation der Chemo- und Strahlentherapie wird international gegenüber der in Deutschland überwiegend praktizierten sequentiellen Applikation der beiden Modalitäten zunehmend der Vorzug gegeben. Idealerweise werden entsprechende Patienten an interdisziplinär aufgestellten Zentren zur Einleitung einer simultanen Chemoradiotherapie vorgestellt. Ein 5-Jahres-Überleben von etwa $20 \%$ ist erreichbar.

\subsection{Stadium IV}

Nach Abschluss der Diagnostik befinden sich mindestens 60\% der Patienten mit SCLC im metastasierten Stadium. Für sie existiert kein kurativer Therapieansatz. Die zytostatische Therapie ist mit primär palliativem Ansatz indiziert. Alle Patienten sollten einer Chemotherapie zugeführt werden. Lediglich Patienten, die eine Chemotherapie ablehnen, oder solche mit einer terminalen Begleiterkrankung sollten ausgenommen werden. Es wird ein Ansprechen des Tumors bei 60-70\% und eine komplette Remission bei 20 - 30\% der Patienten erreicht. Wegen des regelhaft nach einigen Monaten auftretenden Rezidives und der schlechten Ergebnisse der Zweitlinientherapie liegt das mittlere Überleben der Patienten im Stadium IV im Mittel nur bei 9 Monaten.

Zumindest in der Primärtherapie kann durch geeignete Auswahl der Medikamente Rücksicht auf fast jede Vorerkrankung genommen werden, auch auf ein hohes Alter oder einen tumorbedingt schlechten Allgemeinzustand. Zufolge einer Metaanalyse der Behandlungsergebnisse von 4054 Patienten besitzt eine Cisplatin-haltige Chemotherapie einen signifikanten Vorteil bezüglich Ansprechrate und Überleben ohne signifikanten Anstieg der Toxizität im Vergleich zu Cisplatin-freien Kombinationen [33]. Die Kombination von Cisplatin mit Etoposid ist als ein Standard einer Erstlinientherapie des kleinzelligen Lungenkarzinoms akzeptiert. Mit dieser Kombination wird ein mittleres Überleben von etwa 9 Monaten und ein 1-Jahres-Überleben von 30-40\% der Patienten erreicht. Sofern aus Toxizitätsgründen wünschenswert, kann nach dem Ergebnis vergleichender Studien Cisplatin durch Carboplatin bei gleicher Effektivität ersetzt werden. Einen Überblick über weitere, als Standard etablierte Chemotherapieprotokolle, gibt Tab. 4. Der Topoisomeraseinhibitor Irinotecan gilt nach den Studien von Noda [34] und Hanna [39] als möglicher zukünftiger Zulassungskandidat für die First-lineTherapie des SCLC. Der Einsatz von Topotecan/Cisplatin als First-line-Therapie wird derzeit in einer multizentrischen Zulassungsstudie geprüft [40].

Die zusätzliche Applikation von Paclitaxel in einer Dreifachkombination scheint nicht von Vorteil. Vielmehr ist mit einer erhöhten Toxizität zu rechnen. Dies ist das Ergebnis einer aktuellen Phase-III-Studie, in der Cisplatin plus Etoposid gegen die gleiche Kombination plus Paclitaxel getestet wurde [41]. 
Tab. 4 Chemotherapieprotokolle beim kleinzelligen Lungenkarzinom

\begin{tabular}{|c|c|}
\hline \multicolumn{2}{|c|}{ Cisplatin/Etoposid (PE) [34] } \\
\hline Cisplatin & $80 \mathrm{mg} / \mathrm{m}^{2} \mathrm{i}$. v. (Kurzinfusion) Tag 1 \\
\hline Etoposid & $100 \mathrm{mg} / \mathrm{m}^{2}$ i.v. (1-h-Infusion) Tage $1-3$ \\
\hline \multicolumn{2}{|c|}{$\begin{array}{l}\text { Wiederholung alle } 3 \text { Wochen bzw. nach Normalisierung der Blutwerte } \\
\text { normale Nierenfunktion und forcierte Diurese zwingende Voraussetzung }\end{array}$} \\
\hline \multicolumn{2}{|c|}{ Cyclophosphamid/Adriamycin/Vincristin (CAV) [35] } \\
\hline Cyclophosphamid* & $1000 \mathrm{mg} / \mathrm{m}^{2}$ i.v. Tag 1 \\
\hline Adriamycin & $45 \mathrm{mg} / \mathrm{m}^{2} \mathrm{i} . \mathrm{v}$. Tag 1 \\
\hline Vincristin & $2 \mathrm{mg}$ i.v. absolut Tag 1 \\
\hline \multicolumn{2}{|c|}{ Wiederholung alle 3 Wochen unter Berücksichtigung des Blutbildes } \\
\hline \multicolumn{2}{|c|}{ Adriamycin/Cyclophosphamid/Etoposid (ACE) [36] } \\
\hline Adriamycin & $45 \mathrm{mg} / \mathrm{m}^{2} \mathrm{i} . v \cdot \operatorname{Tag} 1$ \\
\hline Cyclophosphamid* & $1000 \mathrm{mg} / \mathrm{m}^{2}$ i.v. Tag 1 \\
\hline Etoposid & $100 \mathrm{mg} / \mathrm{m}^{2}$ i.v. Tage $1-3$ \\
\hline \multicolumn{2}{|c|}{ Wiederholung alle 3 Wochen unter Berücksichtigung des Blutbildes } \\
\hline \multicolumn{2}{|c|}{ Carboplatin/Etoposid [36] } \\
\hline Carboplatin & $300 \mathrm{mg} / \mathrm{m}^{2}$ i.v. (Kurzinfusion) Tag $1^{* *}$ \\
\hline Etoposid & $120 \mathrm{mg} / \mathrm{m}^{2}$ i.v. (1-h-Infusion) Tage 1 - 3 \\
\hline \multicolumn{2}{|c|}{ Wiederholung alle 3 Wochen bzw. nach Normalisierung der Blutwerte } \\
\hline \multicolumn{2}{|c|}{ Carboplatin/Etoposid/Vincristin (CEV) [37] } \\
\hline Carboplatin & $300 \mathrm{mg} / \mathrm{m}^{2}$ i.v. (Kurzinfusion) Tag $1^{* *}$ \\
\hline Etoposid & $140 \mathrm{mg} / \mathrm{m}^{2} \mathrm{i} . v$. (2-h-Infusion) Tage 1 - 3 \\
\hline Vincristin & $1,5 \mathrm{mg}$ i.v. Bolus Tage $1,8,15,22$ \\
\hline \multicolumn{2}{|l|}{ Wiederholung Tag 29} \\
\hline \multicolumn{2}{|l|}{ Etoposid oral [38] } \\
\hline Etoposid & 50 mg/m² p. o. 2-mal/Tag Tag 1 - 10 (14) \\
\hline Wiederholung Tag 22 & \\
\hline
\end{tabular}

* Zur Vermeidung einer Zystitis im Zusammenhang mit Cyclophosphamid i.v. Gabe von Mesna zur Stunde 0 und 4 und 8 Stunden nach der Cyclophosphamidtherapie. Die Mesna-Einzeldosis beträgt jeweils $20 \%$ der Cyclophosphamid-Dosis. Die 2. und/oder 3. Mesna-Dosis kann auch oral gegeben werden. Wegen der verzögerten und inkompletten Resorption beträgt die Mesna-Dosis jeweils $40 \%$ der CyclophosphamidDosis und wird bereits nach 2 bzw. 6 Stunden gegeben.

** Dosierung heute meist nach Ziel-AUC 5, AUC = area under the concentration curve, Berechnung über "Calvert-Formel“

Nach kompletter Remission eines SCLC ist eine prophylaktische Schädelbestrahlung empfohlen.
Ist nach dem ersten Zyklus der Chemotherapie eine Progression zu beobachten, wird unmittelbar auf eine Chemotherapie mit anderen Substanzen umgestellt. Bei Ansprechen werden nach den ersten beiden Zyklen noch zwei bis maximal 4 weitere Zyklen appliziert. Danach wird bis zum erneuten Progress eine Therapiepause eingelegt.

\subsection{Prophylaktische Schädelbestrahlung}

Eine prophylaktische Schädelbestrahlung (PCI) wird beim kleinzelligen Lungenkarzinom nach Eintritt einer kompletten Remission empfohlen [42]. Dadurch wird die Inzidenz von Hirnmetastasen gesenkt. Entsprechend den Ergebnissen einer Metaanalyse von 987 Patienten mit kompletter Remission aus 7 klinischen Studien verbessert die PCI das 3-Jahresüberleben um 5,4\%, absolut stieg das 3-Jahresüberleben von 15,3\% auf 20,7\% [43]. Der Überlebensvorteil bestand auch für Patienten im Stadium extensive disease. Allerdings war der Anteil dieser Patienten in der Metaanalyse mit $12 \% \mathrm{im} \mathrm{Be-}$ strahlungs-Arm und 17\% im Kontroll-Arm relativ gering. Aus den Daten lässt sich schließen, dass die PCI die Entwicklung von Hirnfiliae tatsächlich verhindert und nicht einfach ihre Manifestation hinauszögert. 
Derzeit besteht keine Indikation zu einer Erhaltungstherapie beim SCLC.

Die Wahl der Rezidivtherapie des SCLC ist abhängig von der Dauer der Remission durch die Erstlinientherapie.

\subsection{Erhaltungstherapie}

Eine chemotherapeutische Erhaltungstherapie verbessert die medianen Überlebenszeiten nicht. Ebenso hat sie keinen Einfluss auf die Zahl der Langzeitüberlebenden. Weitere Behandlungsansätze jenseits des chemotherapeutischen Ansatzes (z. B. Vakzinierungsstrategien) befinden sich in klinischer Prüfung.

\subsection{Rezidiv}

Die initialen Ansprechraten auf die Chemotherapie in der Behandlung des kleinzelligen Lungenkarzinoms sind hoch (45\%-75\% komplette Remissionen bei limited disease bzw. 20\%-30\% bei extensive disease). Trotzdem beträgt wegen der hohen Rezidivneigung das progressionsfreie Überleben nur 12 Monate bei limited disease bzw. 4 Monate bei extensive disease. In der Rezidivbehandlung lassen sich zwar immer noch Remissionen und eine Lebensverlängerung erzielen, die mittlere Lebenserwartung ist aber kurz (< 6 Monate). Deshalb muss die Entscheidung über die Durchführung einer erneuten Chemotherapie individuell und in Absprache mit dem Erkrankten getroffen werden.

Beträgt das rezidivfreie Intervall weniger als 6 Monate kann der Wechsel auf ein alternatives Behandlungsprotokoll (z. B. Cyclophosphamid, Adriamycin und Vincristin nach Cisplatin und Etoposid oder umgekehrt) noch zu einer Remission bei bis zu 50\% der Patienten führen. Falls auch mit einem solchen Wechsel keine Remissionen induziert werden, kann eine zytostatische Monotherapie noch wirksam sein. In Betracht kommen neben Etoposid, Vincaalkaloiden und Anthrazyklinen auch Taxane oder Topoisomerase-I-Hemmer. Patienten mit Tumormanifestationen innerhalb eines möglichen Bestrahlungsfeldes können auch bestrahlt werden.

Ist das rezidivfreie Intervall länger als 9-12 Monate, kann die initial verwendete Chemotherapiekombination erneut eingesetzt werden. Insbesondere die prolongierte orale Gabe von Etoposid kann bei guter Verträglichkeit noch eine wirksame Rezidivtherapie darstellen, selbst bei Patienten, die bereits eine etoposidhaltige Kombination erhalten haben.

Seit 1999 [35] liegen positive Daten für die second line Therapie mit Topotecan vor, in Kürze wird die Zulassung in dieser Indikation erwartet.

\subsection{Dosisdichte}

Zur Zeit gibt es außerhalb entsprechender Studienprotokolle keine Berechtigung für dosisintensivierte Protokolle, weder bei limited noch bei extensive disease. Auch der routinemäßige Einsatz von Wachstumsfaktoren (G-CSF) im Rahmen der aufgeführten Chemotherapieprotokolle wird nicht empfohlen.

\section{Schlussbemerkung}

Der Stellenwert der Chemotherapie im Behandlungskonzept der nicht-kleinzelligen Lungenkarzinome ist in den letzten Jahren stetig gestiegen. Abgesehen vom Stadium I des NSCLC ist die Chemotherapie heute in allen anderen Stadien im Rahmen kurativer oder palliativer Konzepte unter Beachtung des Allgemeinzustandes und von Komorbiditäten indiziert. Sowohl beim NSCLC als auch beim SCLC ist im Stadium III eine eng verzahnte („multimodale“) Kombination von Chemotherapie, Strahlentherapie und/ oder Operation die Therapie der Wahl, wobei Sequenz der Modalitäten, chemotherapeutische Substanzen und ihre Dosierung sowie Applikation der Strahlentherapie in klinischen Studien weiter festgelegt werden müssen. Optimal ist in diesen Fällen die Vorstellung geeigneter Patienten in entsprechenden Zentren und Behandlung innerhalb aktuell offener Studienprotokolle. Die molekular zielgerichtete Therapie des Lun- 
genkarzinoms hat soeben mit positiven Phase-III-Studien für den oralen EGFR-Antagonisten Erlotinib und den monoklonalen VEGF-Antikörper Bevacizumab ihren Einzug in die Klinik erfahren.

\section{Literatur}

${ }^{1}$ Felip E, Stahel RA, Pavlidis N. ESMO minimum clinical recommendations for diagnosis, treatment and follow-up of non-small cell lung cancer (NSCLC). Ann Oncol 2005; 16 (Suppl 1): i28-i29

${ }^{2}$ Felip E, Pavlidis N, Stahel RA. ESMO minimum clinical recommendations for diagnosis, treatment and follow-up of small cell lung cancer (SCLC). Ann Oncol 2005; 16 (Suppl 1): i30-i31

${ }^{3}$ Spira A, Ettinger DS. Multidisciplinary management of lung cancer. N Engl J Med 2004; 350: 379-392

${ }^{4}$ Drings P. Therapie des nicht-kleinzelligen Lungenkarzinoms. In: Informationszentrum für Standards in der Onkologie und Deutsche Krebsgesellschaft e.V.: Kurzgefasste interdisziplinäre Leitlinien 2004. München: W. Zuckschwerdt Verlag, 2004: 115-135

${ }^{5}$ Robinson LA, Wagner H, Ruckdeschel JC. Treatment of stage IIIA non-small cell lung cancer. Chest 2003; 123: 202S-220S

${ }^{6}$ Meerbeeck JP, Kramer G, Schil PE vanet al. A randomized trial of radical surgery versus thoracic radiotherapy in patients with stage IIIA-N2 non-small cell lung cancer after response to induction chemotherapy (EORTC 08941). Proc Am Soc Clin Oncol 2005; \#abstract: 7015

${ }^{7}$ Non-small cell lung cancer collaborative group. Chemotherapy in non-small cell lung cancer: a meta-analysis using updated data in individual patients from 52 randomised clinical trials. BMJ 1995; 311: 899-909

${ }^{8}$ The international adjuvant lung cancer trial collaborative group. Cisplatin-based adjuvant chemotherapy in patients with completely resected non-small-cell lung cancer. N Engl J Med 2004; 350: $351-360$

${ }^{9}$ Winton T, Livingston R, Johnson Det al. Vinorelbine plus cisplatin vs. observation in resected non-small-cell lung cancer. N Engl J Med 2005; 352: 2589-2597

${ }^{10}$ Strauss GM, Herndon J, Maddaus MAet al. Randomized clinical trial of adjuvant chemotherapy with Paclitaxel and Carboplatin following resection in stage IB non-small-cell lung cancer: report of cancer and leukaemia group B (CALGB) protocol 9633. Proc Am Soc Clin Oncol 2004; \#abstract: 7019

${ }^{11}$ Douillard JY, Rosell R, Lena M deet al. ANITA: Phase III adjuvant vinorelbine and cisplatin versus observation in completely resected (stage I- III) non-small cell lung cancer patients: final results after 70-month median follow up. On behalf of the adjuvant navelbine international trialist association. Proc Am Soc Clin Oncol 2005; \#abstract: 7013

12 Pfister DG, Johnson DH, Azzoli CGet al. American Society of Clinical Oncology treatment of unresectable non-small-cell lung cancer guidelines: update 2003. J Clin Oncol 2004; 22: $330-353$

${ }^{13}$ Farray D, Mirkovic N, Albain KS. Multimodality therapy for stage III non-small-cell lung cancer. J Clin Oncol 2005; 23: 3257-3269

14 Belani CP, Wang W, Johnson DHet al. Phase III study of the eastern cooperative oncology group (ECOG 2597): induction chemotherapy followed by either standard thoracic radiotherapy or hyperfractionated accelerated radiotherapy for patients with unresectable stage IIIA and B non-small-cell lung cancer. J Clin Oncol 2005; 23: 3760-3767

${ }^{15}$ Stamatis G, Eberhardt W, Pöttgen C. Surgery after multimodality treatment for non-small-cell lung cancer. Lung Cancer 2004; 45, S2: S107-S112

${ }^{16}$ Gaspar LE, Chansky K, Albain KSet al. Time from treatment of subsequent diagnosis of brain metastases in stage III non-small-cell lung cancer: a retrospective review by southwest oncology group. J Clin Oncol 2005; 23: 2955-2961

${ }^{17}$ Schiller JH, Harrington D, Belani CPet al. Comparison of four chemotherapy regimens for advanced non-small-cell lung cancer. N Engl J Med 2002; 346: 92 - 98

${ }^{18}$ Fossella F, Pereira JR, Pawel J vonet al. Randomized, multinational, phase III study of docetaxel plus platinum combinations versus vinorelbine plus cisplatin for advanced non-small-cell lung cancer: the tax 326 study group. J Clin Oncol 2003; 21: 3016-3024

${ }^{19}$ Kelly K, Crowley J, Bunn PAet al. Randomized phase III trial of paclitaxel plus carboplatin versus vinorelbine plus cisplatin in the treatment of patients with advanced non-small-cell lung cancer: a southwest oncology group trial. J Clin Oncol 2001; 19: 3210-3218

${ }^{20}$ Rosell R, Gatzemeier U, Betticher DCet al. Phase III randomised trial comparing paclitaxel/carboplatin with paclitaxel/cisplatin in patients with advanced non-small-cell lung cancer: a cooperative multinational trial. Ann Oncol 2002; 13: 1539-1549

${ }^{21}$ Pujol JL, Breton JL, Gervais Ret al. Gemcitabine-docetaxel versus cisplatin-vinorelbine in advanced or metastatic non-small-cell lung cancer: a phase III study addressing the case for cisplatin. Ann Oncol 2005; 16: $602-610$

22 Laack E, Dickgreber N, Müller Tet al. Randomized phase III study of gemcitabine and vinorelbine versus gemcitabine, vinorelbine, and cisplatin in the treatment of advanced non-smallcell lung cancer: from the german and swiss lung cancer study group. J Clin Oncol 2004; 22: $2348-2356$ 
${ }^{23}$ Kosmidis P, Mylonakis N, Nicolaides Cet al. Paclitaxel plus carboplatin versus gemcitabine plus paclitaxel in advanced non-small-cell lung cancer: a phase III randomized trial. J Clin Oncol 2002; 20: $3578-3585$

${ }^{24}$ Socinski MA, Morris DE, Masters GAet al. Chemotherapeutic management of stage IV nonsmall cell lung cancer. Chest 2003; 123: 226S-243S

${ }^{25}$ Gridelli C, Aapro M, Ardizzoni Aet al. Treatment of advanced non-small-cell lung cancer in the elderly: results of an international expert panel. J Clin Oncol 2005; 23: 3125 - 3137

${ }^{26}$ Shepherd FA, Dancey J, Ramlau Ret al. Prospective randomized trial of docetaxel versus best supportive care in patients with non-small-cell lung cancer previously treated with platinumbased chemotherapy. J Clin Oncol 2000; 18: 2095-2103

${ }^{27}$ Fossella FV, DeVore R, Kerr RNet al. Randomized phase III trial of docetaxel versus vinorelbine or ifosfamide in patients with advanced non-small-cell lung cancer previously treated with platinum-containing chemotherapy regimens. J Clin Oncol 2000; 18: 2354-2362

${ }^{28}$ Hanna N, Shepherd FA, Fossella FVet al. Randomized phase III trial of pemetrexed versus docetaxel in patients with non-small-cell lung cancer previously treated with chemotherapy. J Clin Oncol 2004; 22: 1589-1597

${ }^{29}$ Fischer B, Fischer T, Baumann Met al. Molekulare Zielstrukturen für die Therapie des Bronchialkarzinoms. Onkologe 2002; 8: 494-501

${ }^{30}$ Shepherd FA, Pereira JR, Ciuleanu Tet al. Erlotinib in previously treated non-small-cell lung cancer. N Engl J Med 2005; 353: $123-132$

31 Sandler AB, Gray R, Brahmer Jet al. Randomized phase II/III trial of Paclitaxel plus Carboplatin with or without bevacizumab in patients with advanced non-squamous non-small cell lung cancer: an eastern cooperative oncology group (ECOG) trial - E4599. Proc Am Soc Clin Oncol 2005; \#abstract: LBA4

${ }^{32}$ Page NC, Read WL, Tierney RMet al. The epidemiology of small cell lung carcinoma. Proc Am Soc Clin Oncol 2002; 21: 305a

${ }^{33}$ Pujol JL, Carestia L, Daures JP. Is there a case for cisplatin in the treatment of small-cell lung cancer? A meta-analysis of randomized trials of a cisplatin-containing regimen versus a regimen without this alkylating agent. Br J Cancer 2000; 83: 8-15

${ }^{34}$ Noda K, Nishiwaki Y, Kawahara Met al. Irinotecan plus cisplatin compared with etoposide plus cisplatin for extensive small-cell lung cancer. N Engl J Med 2002; 346: 85-91

${ }^{35}$ Pawel J von, Schiller JH, Shepherd FAet al. Topotecan versus cyclophosphamide, doxorubicin, and vincristine for the treatment of recurrent small-cell lung cancer. J Clin Oncol 1999; 17: $658-667$

${ }^{36}$ Manegold C. Chemotherapie des kleinzelligen Bronchialkarzinoms. Onkologe 1998; 4: $1019-1029$

${ }^{37}$ Eberhardt W, Seeber S, Niederle N. CEV - ein wirksames Regime zur Therapie von Patienten mit fortgeschrittenen kleinzelligen Bronchialkarzinomen. In: Hellriegel KP, Seeber S (Hrsg.). Neue Aspekte für die Chemotherapie von Malignomen. (Aktuelle Onkologie) Bd. 70. München, Bern, Wien, New York: Zuckerschwerdt, 1993: 1-7

${ }^{38}$ Clark PI, Cottier B. The activity of 10,14, and 21-day schedules of single agent etoposide in previously untreated patients with extensive small cell lung cancer. Semin Oncol 1992; 19 (Suppl 14): $36-39$

${ }^{39}$ Hanna NH, Einhorn L, Sandler Aet al. Randomized, phase III trial comparing irinotecan/cisplatin (IP) with etoposide/cisplatin (EP) in patients (pts) with previously untreated, extensivestage (ES) small cell lung cancer (SCLC). Proc Am Soc Clin Oncol 2005; \#abstract: 7004

${ }^{40}$ Wolf M, Tebbe S, Fink T. First-line chemotherapy in metastatic small-cell lung cancer (SCLC). Lung Cancer 2004; 45 Suppl. 2: S223 -S234

${ }^{41}$ Niell HB, Herndon II JE, Miller AAet al. Randomized phase III intergroup trial of etoposide and cisplatin with or without paclitaxel and granulocyte colony-stimulating factor in patients with extensive-stage small-cell lung cancer: CALGB trial 9732. J Clin Oncol 2005; 23: $3752-3759$

42 Simon GR, Wagner H. Small cell lung cancer. Chest 2003; 123: 259S-271S

${ }^{43}$ Auperin A, Arriagada R, Pignon JPet al. Prophylactic cranial irradiation for patients with smallcell lung cancer in complete remission. N Engl J Med 1999; 341: 476-484

\section{Dr. B. Fischer}

III. Medizinische Klinik und Poliklinik · Schwerpunkt Pneumologie ·

Universitätskliniken Mainz

Langenbeckstr. 1

55131 Mainz

E-mail: b.fischer@3-med.klinik.uni-mainz.de 
Wie hoch ist ungefähr das 5-JahresÜberleben aller Patienten mit Lungenkarzinom? NSCLC ist falsch:
A $5 \%$
B $15 \%$
C $20 \%$
D $30 \%$
E $50 \%$

Welche Aussage zum Stadium I/II des

A Das Stadium I/II des NSCLC wird nach Möglichkeit primär operiert.

B Wenn technisch möglich, sollte bei entsprechender Tumorlokalisation eine Manschettenresektion einer Pneumektomie vorgezogen werden.

C Wenn eine Resektion nicht erfolgen kann, z. B. bei schweren Begleiterkrankungen oder fehlendem Einverständnis, sollte eine kurativ angelegte Bestrahlung vorgeschlagen werden.

D Bei Tumorinfiltration in den Schnitträndern sollte eine Nachresektion erfolgen. Alternativ besteht die Möglichkeit einer Nachbestrahlung.

E Im Stadium I/II des NSCLC wird für die klinische Routine eine präoperative Chemotherapie empfohlen.

A Suspekte mediastinale Lymphknoten sollten wegen der erheblichen therapeutischen Konsequenzen bioptisch gesichert werden (z. B. Mediastinoskopie oder transbronchiale Nadelaspiration).

B Bei multiplem mediastinalem Lymphknotenbefall (IIIA, $\mathrm{N}_{2}$ multipel) ist nach Möglichkeit die multimodale Therapie innerhalb einer klinischen Studie angezeigt.

C Derzeit gibt es keine allgemein akzeptierte Therapiesequenz für das Stadium IIIA, $\mathrm{N}_{2}$ mit multiplen Lymphknotenmetastasen.

D Multimodale Therapiekonzepte können unabhängig vom Allgemeinzustand und Komorbidität durchgeführt werden.

E Außerhalb klinischer Studien empfehlen die aktuellen Leitlinien der European Society for Medical Oncology (2005) bei Operabilität eine neoadjuvante Chemotherapie.

A Die adjuvante Chemotherapie wird grundsätzlich als Monotherapie durchgeführt.

B Es gibt keine therapieassoziierte Letalität durch die adjuvante Chemotherapie.

C Die adjuvante Chemotherapie empfiehlt sich etwa 4-6 Wochen postoperativ nach weitgehender Erholung des Patienten.

D Die adjuvante Chemotherapie findet nur im Stadium III Anwendung.

E Cisplatin ist wegen seiner bekannten Toxizität nicht geeignet. 
Prüfen Sie folgende Aussagen zum NSCLC:
Ein 60-jähriger Anwalt stellt sich wegen Gliederschmerzen, Husten und Belastungsdyspnoe auf Drängen seiner Ehefrau zur Abklärung vor. Vorerkrankungen sind nicht bekannt. Der Patient hat $7 \mathrm{~kg}$ Gewicht in 6 Monaten abgenommen (etwa 10\% des $K G)$. Er war bis vor einem Jahr Raucher und hat 37 pack years geraucht. Seine berufliche Tätigkeit übt er nach eigenen Angaben ohne wesentliche Einschränkungen weiterhin aus. Die komplette Durchuntersuchung ergibt ein großzelliges Lungenkarzinom (NSCLC) mit neuroendokriner Differenzierung im Stadium IV ( $\left.\mathrm{CT}_{3} \mathrm{CN}_{2} \mathrm{CM}_{1 \text { pulm multipel }}\right)$. Leberfunktion, Nierenfunktion und Blutbild sind unauffällig. Prüfen Sie die folgenden Aussagen:

Welche Aussage zum kleinzelligen Lungenkarzinom (SCLC) ist falsch?
Im Stadium IIIB mit malignem Pleuraerguss oder Perikarderguss erfolgt wie im Stadium IV eine palliative Chemotherapie weil durch die Ergussbildung keine kurative Lokaltherapie (Bestrahlung, Operation) mehr erfolgen kann.

A Beide Aussagen sind falsch.

B Nur die erste Aussage ist richtig.

C Nur die zweite Aussage ist richtig.

D Beide Aussagen sind richtig, aber die Verknüpfung ist falsch.

E Beide Aussagen und die Verknüpfung sind richtig.

1. Eine palliative Chemotherapie ist indiziert.

2. Eine platinhaltige Kombinationstherapie mit einer der neueren Zytostatika (Drittgenerationstherapeutika) ist empfohlen.

3. Bei Ansprechen werden 3-4 Zyklen der Chemotherapie empfohlen.

4. Bei einem Rezidiv ist bei weiterhin gutem Allgemeinzustand eine Zweitlinientherapie empfohlen.

5. Als Zweilinientherapie kommt zum Beispiel eine Therapie mit Docetaxel oder Pemetrexed infrage.

A Alle Aussagen sind richtig.

B Nur Aussage 1 ist richtig.

C Aussagen 1, 4 und 5 sind richtig.

D Aussagen 1, 2 und 3 sind richtig.

E Alle Aussagen sind falsch.

A Bei ca. 15\%-20\% aller Lungenkarzinome liegt ein SCLC vor.

B Die kombinierte Chemoradiotherapie im Stadium limited disease erfolgt nur in klinischen Studien.

C Die Stadieneinteilung erfolgt in limited und extensive disease.

D Eine Resektion ist in den Stadien I und II zu empfehlen.

E Die führende Behandlungsmodalität stellt die Chemotherapie dar. 
Im Stadium limited disease des SCLC besteht eine kurative Therapieintention

weil

bis zu $20 \%$ der Patienten fünf Jahre überleben können.

9

Welche Aussage zum SCLC, extensive disease ist richtig?

Bei Patienten mit SCLC ist nach Eintritt einer kompletten Remission eine prophylaktische Schädelbestrahlung indiziert

weil

nach den Ergebnissen einer Meta-

analyse das 3-Jahresüberleben um

absolut ca. $5 \%$ verbessert wird.
A Beide Aussagen sind falsch.

B Nur die erste Aussage ist richtig.

C Nur die zweite Aussage ist richtig.

D Beide Aussagen sind richtig, aber die Verknüpfung ist falsch.

E Beide Aussagen und die Verknüpfung sind richtig.

A Eine Erhaltungstherapie verbessert nicht die Überlebenszeit.

B Das mittlere Überleben im Stadium extensive disease beträgt etwa 24 Monate.

C Etwa 30\% aller SCLC befinden sich bei Diagnosestellung im Stadium extensive disease.

D Mono-Chemotherapie und Kombinations-Chemotherapie sind gleich effektiv.

E Rezidive müssen immer mit alternativen Chemotherapiekombinationen behandelt werden.

A Beide Aussagen sind falsch.

B Nur die erste Aussage ist richtig.

C Nur die zweite Aussage ist richtig.

D Beide Aussagen sind richtig, aber die Verknüpfung ist falsch.

E Beide Aussagen und die Verknüpfung sind richtig. 


\section{A. Angaben zur Person}

Online-Teilnahme unter http://cme.thieme.de

\section{B. Didaktisch-methodische Evaluation}

Name, Vorname, akad. Titel:

Straße, Hausnr.: PLZ/Ort:

Ich bin Mitglied der Ärztekammer:

Jahr meiner Approbation:

Ich befinde mich in der Weiterbildung zum:

Ich habe eine abgeschlossene Weiterbildung in/für:

seit/Jahr der Facharztanerkennung:

Spezialisierung innerhalb des Fachgebiets: $\square$ nein $\square$ ja, welche?

Ich möchte folgende Zusatzbezeichnungen erwerben:

Ich habe folgende Zusatzbezeichnungen: seit:

Ich bin tätig als:

$\square$ Assistenzarzt $\square$ Oberarzt $\square$ Chefarzt in folgender Klinik:

$\square$ Niedergelassener Arzt, seit $\square$ im Ballungsraum $\square$ im ländlichen Raum

$\checkmark$ Sonstiges (bitte eintragen):

Führen Sie in Ihrer Praxis diagnostische und therapeutische Auftragsleistungen im Bereich des Fortbildungsthemas durch?

$\square$ nein $\square$ ja, welche?

Bieten Sie in der Diagnostik und Therapie im Bereich des Fortbildungsthemas Besonderheiten in Ihrer Praxis/Klinik an?

$\square$ nein $\square$ ja, welche?

Machen Sie diese ggf. als Praxisbesonderheiten geltend?

$\square$ nein $\square$ ja, welche?

Ich bin Abonnent: $\square$ ja $\square$ nein, der Fragebogen ist aus/von: $\square$ Zeitschrift $\square$ thieme-connect $\square$ Kollegen $\square$ der Klinik $\square$ der Bibliothek $\square$ Sonstiges

1. Wie viele Patienten diagnostizieren/behandeln Sie im Zusammenhang mit dem Fortbildungsthema pro Jahr?

2. Bitte benennen Sie die 3 wichtigsten für Sie noch offenen Probleme in der Diagnostik des Fortbildungsthemas:

3. Bitte benennen Sie die 3 wichtigsten für Sie noch offenen Probleme in der Therapie des Fortbildungsthemas:

4. Bezüglich der Diagnostik/Behandlung im Rahmen des Fortbildungsthemas $\square$ fühle ich mich nach Studium des Beitrages in meiner Strategie bestätigt. $\square$ hat sich meine Strategie folgendermaßen verändert - bitte benennen: 


\begin{tabular}{l} 
Ihr Ergebnis \\
(wird vom Verlag ausgefüllt) \\
Sie haben_ von__ Fragen \\
richtig beantwortet und somit \\
$\square$ bestanden und 3 CME-Punkte \\
erworben \\
$\square$ nicht bestanden. \\
Stuttgart, \\
\hline (Stempel/Unterschrift) \\
zertifiziert durch die Ärztekammer \\
Nordrhein
\end{tabular}

C. Lernerfolgskontrolle (nur eine Antwort pro Frage ankreuzen)
5. Wurden aus der Sicht Ihrer täglichen Praxis wichtige Aspekte des Themas
a) außer Acht gelassen? $\square$ nein $\square$ ja, welche?
b) zu knapp abgehandelt? $\square$ nein $\square$ ja, welche?
c) überbewertet? $\square$ nein $\square$ ja, welche?

6. Etwa wieviel Prozent des Beitrages haben Ihnen

a) zur Auffrischung bereits bekannten Wissens gedient:

$a<10 \% \quad \square<25 \% \quad \square<50 \% \quad \square \geq 50 \%$

b) zur Erweiterung Ihres Spezialwissens gedient:

$\square<10 \% \quad \square<25 \% \quad \square<50 \% \quad \square \geq 50 \%$

7. Die Diagnostik/Therapie im Zusammenhang mit dem Fortbildungsthema wird $\square$ von mir begonnen und vom Hausarzt weitergeführt.

$\square$ von mir begonnen und bis zur endgültigen Diagnosestellung bzw. Therapieeinstellung durchgeführt.

๑ Diagnostik, Therapie und Langzeitkontrolle erfolgen durch mich

(in Abstimmung mit dem Hausarzt).

$\square$ von mir überwiegend als Auftrags-/Konsiliarleistung erbracht.

8. Für die Diagnostik/Therapie zum Fortbildungsthema ziehe ich regelmäßig andere Fachgruppen hinzu. $\square$ nein $\square$ ja, welche?

9. Ergeben sich für Sie aus wirtschaftlichen Gründen Limitierungen im Einsatz von im Beitrag genannten Diagnose-/Therapieverfahren?

$\square$ nein $\square$ ja, welche?

10. Stehen Ihnen aus logistischen Gründen im Beitrag genannte Diagnose-/Therapieverfahren nicht/nur eingeschränkt zur Verfügung?

$\square$ nein $\square$ ja, welche?

11. Die Fragen lassen sich

$\square$ aus dem Studium des Beitrages allein beantworten.

$\square$ nur unter Zuhilfenahme zusätzlicher Literatur beantworten.

12. Ich habe für die Bearbeitung dieser Fragen (inkl. Antwortbogen) Minuten benötigt.

$\begin{array}{rrrrrrrrrrrr}\mathbf{1} & \text { A } & \text { B } & \text { C } & \text { D } & \text { E } & \mathbf{6} & \text { A } & \text { B } & \text { C } & \text { D } & \text { E } \\ \mathbf{2} & \text { A } & \text { B } & \text { C } & \text { D } & \text { E } & \mathbf{7} & \text { A } & \text { B } & \text { C } & \text { D } & \text { E } \\ \mathbf{3} & \text { A } & \text { B } & \text { C } & \text { D } & \text { E } & \mathbf{8} & \text { A } & \text { B } & \text { C } & \text { D } & \text { E } \\ \mathbf{4} & \text { A } & \text { B } & \text { C } & \text { D } & \text { E } & \mathbf{9} & \text { A } & \text { B } & \text { C } & \text { D } & \text { E } \\ \mathbf{5} & \text { A } & \text { B } & \text { C } & \text { D } & \text { E } & \mathbf{1 0} & \text { A } & \text { B } & \text { C } & \text { D } & \text { E }\end{array}$

\section{Erklärung}

Ich versichere, dass ich die Beantwortung der Fragen selbst und ohne fremde Hilfe durchgeführt habe.

Ort/Datum

Unterschrift

Nichtabonnenten bitte hier CME-Wertmarke aufkleben bzw. Abonnentennummer eintragen
Bitte senden Sie den vollständig ausgefüllten Antwortbogen und einen an Sie selbst adressierten und ausreichend frankierten Rückumschlag an den Georg Thieme Verlag KG, CME, Joachim Ortleb, Postfach 301120, 70451 Stuttgart. Einsendeschluss ist der 30. November 2006 (Datum des Poststempels). Die Zertifikate werden spätestens 14 Tage nach Erhalt des Antwortbogens versandt. Von telefonischen Anfragen bitten wir abzusehen. 
Für diese Fortbildungseinheit erhalten Sie 3 Fortbildungspunkte im Rahmen des Fortbildungszertifikates der Ärztekammern. Hierfür

- müssen $80 \%$ Fragen richtig beantwortet sein.

- müssen die Fragen der Einheiten A bis D des Evaluationsbogens vollständig ausgefüllt sein. Unvollständig ausgefüllte Bogen können nicht berücksichtigt werden!

- muss Ihre Abonnentennummer im entsprechenden Feld des Antwortbogens angegeben oder eine CME-Wertmarke im dafür vorgesehenen Feld aufgeklebt sein.

\section{CME-Wertmarken}

CME-Wertmarken (für Teilnehmer, die die Zeitschrift Pneumologie nicht abonniert haben) können beim Verlag zu folgenden Bedingungen erworben werden: 6er-Pack Thieme-CME-Wertmarken, Preis 63,- Euro inkl. MwSt., Artikel-Nr. 901916; 12er-Pack Thieme-CME-Wertmarken, Preis 99,- Euro inkl. MwSt., Artikel-Nr. 901917. Bitte richten Sie Bestellungen an: Georg Thieme Verlag, Kundenservice, Postfach 301120, 70451 Stuttgart.

\section{Datenschutz}

Ihre Daten werden ausschließlich für die Bearbeitung dieser Fortbildungseinheit verwendet. Es erfolgt keine Speicherung der Ergebnisse über die für die Bearbeitung der Fortbildungseinheit notwendige Zeit hinaus. Die Daten werden nach Versand der Testate anonymisiert. Namens- und Adressangaben dienen nur dem Versand der Testate. Die Angaben zur Person dienen nur statistischen Zwecken und werden von den Adressangaben anonymisiert verarbeitet.

\section{Wichtige Hinweise}

Die CME-Beiträge der Pneumologie wurden durch die Landesärztekammer Nordrhein anerkannt. Die Zeitschrift für Pneumologie ist zur Vergabe der Fortbildungspunkte für diese Fortbildungseinheit berechtigt. Diese Fortbildungspunkte der Landesärztekammer Nordrhein werden von anderen zertifizierenden Ärztekammern anerkannt. Die Vergabe der Fortbildungspunkte ist nicht an ein Abonnement gekoppelt!

\section{Ausschneiden und schicken an: Georg Thieme Verlag, Kundenservice, Postfach 3011 20, 70451 Stuttgart Tel.: 0711/8931-333, Fax: 0711/8931-133, E-mail: Kundenservice@thieme.de}

Anschrift $\square$ privat $\square$ dienstlich
Titel, Name, Vorname:
Straße, Hausnr.:
PLZ/Ort:
ja, ich bestelle:
$\square$ Thieme-CME-Wertmarken 6er-Pack, Preis 63,- Euro inkl. MwSt. und Versand,
Artikel-Nr. 901916
aThieme-CME-Wertmarken 12er-Pack, Preis 99,- Euro inkl. MwSt. und Versand,
Artikel-Nr. 901917
Ort/Datum:
Unterschrift/Stempel:
Preisänderungen und Irrtümer vorbehalten!

